\title{
Assessment of quality of care in maternal and newborn health services available in public health care facilities in Bangladesh
}

\author{
Sameena Chowdhury ${ }^{1}$, Syed Akram Hossain ${ }^{2}$ and Abdul Halim ${ }^{3}$ \\ ${ }^{1}$ Deartment of Obstetrics and Gynecology, Institute of Child and Mother Health, Dhaka; ${ }^{2}$ Department of \\ Oncology, Bangabandhu Sheikh Mujib Medical University, Shahbag, Dhaka, ${ }^{3}$ Department of Obstetrics and \\ Gynecology, Kumudini Woman Medical College, Mirzapur, Tangail, Bangladesh.
}

\begin{abstract}
The study was conducted using the exit interview with patients $(n=120)$, in depth interview with health care providers $(n=87)$ and focus group discussion $(n=16)$ with stakeholders to assess the perceived level of quality of care in maternal and newborn health at public facilities in Bangladesh. Both clients and providers expressed dissatisfaction for inadequate quality of care represented by poor cleanliness, long waiting time with less consultation time, poor compassion by providers, inadequate supply of drugs and unnoticed cost for services varied by level of facilities. Inadequacy in human resource and absenteeism and poor laboratory service were reported to worsen the condition especially at lower level of service delivery. Thus this study explored some important factors like poor quality of care, inadequate technical competencies, information exchange and follow-up services. A deficit in supplies and logistics are strong barrier in regards to quality of care at various levels which needs to be addressed immediately.
\end{abstract}

\section{Introduction}

The maternal mortality ratio (3.2 per 1000 live births) and neonatal mortality ratio (37\%) are still unacceptably high in Bangladesh ${ }^{1,2}$. Though under 5 mortality (65 per 1000 live births) decreased significantly during recent decades, the neonatal mortality ratio did not decreased much ${ }^{2}$.

Government of Bangladesh has a unique health infrastructure from national to community level with very little access to basic healthcare by more than 60 percent of the population ${ }^{3}$. Poor access is still a major challenge in maternal and newborn health especially at peripheral level. The main constraints are inadequate skilled human resource and its management: training, supervision, monitoring and accountability in one hand and poor quality of care, supplies and support in the other.

Continuum of care i.e. appropriate childhood care, adolescent care, then antenatal, natal and postnatal care by skilled provider is crucial. About 56 percent of the pregnant women receive at least one antenatal care from a provider (trained or untrained). Antenatal care coverage has been increasing with time; in 2000 only one third had reported receiving antenatal care from a medically trained person ${ }^{4}$. Only $18 \%$ births in Bangladesh are attended by skilled attendants like doctors, trained nurses, or midwives where only $15 \%$ deliveries occur at a health facility ${ }^{5} .21 .3$ percent of mothers receive post-natal care ${ }^{5}$. The major causes of high maternal mortality are post-partum hemorrhage, eclampsia, complications of unsafe abortion, obstructed labor, post-partum sepsis and violence and injuries ${ }^{6}$.

Interventions to improve access and quality of care at all levels could lead to significant reduction in maternal deaths and thus adopting steps through these interventions, the country can significantly accelerate reduction of maternal mortality ratio as well as under 5 mortality ratio including neonatal mortality ratio ${ }^{7}$. However, both access to and quality of maternal and newborn health care by levels is yet to be optimized in Bangladesh. Therefore, an assessment of the maternal and newborn health status and underlying facts would be crucial to improve the condition.

This study aimed to assess the quality of maternal and newborn health care provided at various levels of public facilities in Bangladesh. It is also aimed to explore the perceptions of both women, family, 
stakeholders and the providers/managers to identify barriers and possible solutions for improving quality of care.

\section{Materials and Methods}

This study was a cross sectional descriptive type of study using both qualitative and qualitative methods. It was conducted in two tertiary level, 4 district level, 4 upazilla level and 4 union level health facilities.

Married women of reproductive age group attending the selected facilities for maternal and newborn health care were randomly selected for exit interview using pre-tested questionnaire.

Women of reproductive age group (beneficiaries, $n=120)$ and providers $(n=87)$ of various levels (doctors, nurses, FWVs, specialists, etc) were observed and interviewed from the selected facilities to collect baseline information. In depth interview and focus group were conducted with providers, managers; and beneficiaries etc at various levels by a trained research team. Table I represents the sample of study.

Table I: Sample size and characteristics

\begin{tabular}{l|ccc}
\hline $\begin{array}{l}\text { Level } \\
\text { (number) }\end{array}$ & $\begin{array}{c}\text { Exit } \\
\text { interview } \\
\text { No. of } \\
\text { clients }\end{array}$ & $\begin{array}{c}\text { In depth } \\
\text { interviews } \\
\text { No. of } \\
\text { providers }\end{array}$ & $\begin{array}{c}\text { No of } \\
\text { FGDs }\end{array}$ \\
\hline $\begin{array}{l}\text { Medical College Hospital (2) } \\
\text { District hospitals (2) \& } \\
\text { MCWCs (2) }\end{array}$ & 25 & 16 & 4 \\
$\begin{array}{l}\text { Upazilla health complex (4) } \\
\begin{array}{l}\text { Union health and family } \\
\text { welfare center (4) }\end{array}\end{array}$ & 31 & 26 & 4 \\
\hline Total & 120 & 87 & 4 \\
\hline
\end{tabular}

The in depth interviews ( $n=87$ ) were conducted by trained research assistants using pre-tested guidelines and tools. In depth interviews were conducted with service providers $(n=87)$ of various categories working in medical colleges $(n=2)$; district hospital/MCWCs $(\mathrm{n}=4)$; upazilla health complexes $(n=4)$ and union health and family welfare centers $(n=4)$. Sixteen FGDs were conducted at medical colleges, district, upazilla and union health facilities (Table I) to understand perception of community people and providers as regard quality of maternal and newborn health care.

The quality of care at facility level was assessed by using variables as reported by the clients on exit interview: like cleanliness of hospital environment, mean waiting time to see doctors (within expected time of $30 \mathrm{~min}$ ), availability of laboratory test for them, consultation time, and satisfaction on over all services available.

The study used pre-tested data collection tools by a trained data collector team. Due ethical consideration were undertaken. All the information collected and edited at field level and then data entry were done and analyzed using Epi-info soft ware. Qualitative data of the Focus Group Discussion (FGD) were transcribed from notes or audio recording into text and processed into general themes and quality of care indicators.

\section{Results}

The mean age of participants in exit interview was $26.3 \pm 7.4$ years. $89 \%$ of them were house wife and rests were job holders, house hold worker and students. $32 \%$ of clients in the medical college hospitals, $38.5 \%$ in the district level facilities (district hospital and MCWC), $38.7 \%$ in the upazilla facilities and $44 \%$ in union facilities reported that cleanliness was satisfactory.

Only $45.2 \%$ of clients reported to receive some types of drugs from the facilities. Mean waiting time across the facilities (Table II) was $39.9 \pm 40.1$ min. $22.7 \%$ reported they had some laboratory test done in the facilities.

Table II: Mean waiting time (as reported by the clients under exit interview) and consultation time (offered by health care providers)

\begin{tabular}{l|cc}
\hline & $\begin{array}{c}\text { Waiting } \\
\text { time (min) }\end{array}$ & $\begin{array}{c}\text { Consultation } \\
\text { time (min) }\end{array}$ \\
\hline Medical college hospital & 14 & 11 \\
District hospital /MCWC & 33 & 12 \\
Upazilla health complex & 47 & 9 \\
$\begin{array}{l}\text { Union health and family } \\
\text { welfare center }\end{array}$ & 54 & 8 \\
\hline
\end{tabular}

Medical college hospitals provided more laboratory services (68.4\%) while union health and family welfare centers offered the lowest (20.0\%). 76\% (ranging from $64.5 \%$ to $84.6 \%$ across the facilities) of the clients got consultation from their physicians in expected time. Mean time offered by the doctors was $8.9 \pm 4.8 \mathrm{~min}$. $43.3 \%$ of clients (ranging from $36 \%$ in medical college to $56 \%$ in union facilities) reported that their providers gave satisfactory briefing on their problems and/or treatment. 84\% of the clients reported receiving services from female providers while $46.1 \%$ said that their providers had smiling attitude. Majority reported that their providers had helping attitude (84.8\%).

Those who are not satisfied, they blamed cool behavior of HCP (\%), non-availability of drug (\%), poor or no toilet facilities (93.\%), unclean 
bed \& beddings ( \%) and unexpected expenditure (like bribe, tips etc) in facilities (43\%).

Ninety two percent of the providers claimed to accomplish good conduct with their clients, while $74 \%$ stated that overcrowding and non-congenial hospital environment hampers the quality of work. Other constrains includes deficit supplies/drugs, non functioning/non-availability of ambulance services, 24 hours blood transfusion services, quality laboratory services especially ultrasonography for pregnant woman. Inadequate skilled specialists: anesthetists and obstetricians, nurses and support staff were identified as the important barriers to quality maternal and newborn health services. Laboratory investigations, counselors, adequate staff accommodation, poor fund, and separate outdoor services for maternal and newborn health were also noted as constrain at level especially in the district and upazilla hospitals. Providers in upazilla hospitals reported dissatisfaction for frequent transfer of key human resources like anesthetist/obstetrician or both leading to a non-functioning EmOC centre.

FGD with family members and beneficiaries identified service related cost to purchasing drugs, getting treatment from hospital and transportation for referral as the strongest barrier. Majority providers participated in the FGDs reported on shortage of doctors, nurses and other support staff at facilities. The cool behave, late-coming, short time staying or absenteeism of the providers took much attention in the discussion especially for peripheral facilities. The groups also stated that some informal attendants like Ayas and/or agents create non-congenial environment at upazilla and above level facilities by asking bribe or tips.

Focus group also reported of inadequate supplies, equipments and logistics at all level of facilities. Scarcity of lady doctor and their retention at place is another problem. Continuous availability of doctors, drugs, good behave of providers and cleanliness were the common demand for improvement of services.

\section{Discussion}

Bangladesh has made substantial progress maternal and newborn health in the recent years. The progress can be much accelerated if the quality of care be ensured at facilities. Commonly perceived constrain lies in the quality of care provided by public facilities especially in maternal and newborn health. The current study included a strategic approach for rapid assessment of level of quality in care being provided by various levels of public facility that revealed a clear indication for improvement. The low status in quality of maternal and newborn health care ultimately reflects poor impact of the huge Govt. health infrastructure and its manpower on ultimate improvement of maternal and neonatal health.

The current study was a rapid and in a smaller scale effort being conducted systematically using both qualitative and quantitative methods to explore gaps at ground level. It also explored the existing barriers to quality of maternal and newborn health care- like patient-provider relationship, the technical competencies, access to information, follow-up services, and management issues including supplies and logistics.

The majority of the clients/beneficiaries, stakeholders and even the HCPs in general agreed that the care provided by the facilities in the field of maternal and newborn health is poor in quality and did not reach their level of satisfaction.

Lacking cleanliness, longer waiting time and less consultation time with doctors, non or irregular availability of drugs, involvement of unnoticed cost for services, inadequate staff were identified as prime cause for dissatisfaction by the clients. Absenteeism of providers at lower level facilities were reported to be higher and held for dissatisfaction and poor services. Higher waiting time at union level was also noticed. The laboratory services are more available at higher level of facilities like district and medical college hospitals while the upazilla and union did the least. The providers strongly pointed out that the offered time and behaving with smile and helping attitude was quite poor that needs to be addressed to improve quality in maternal and newborn health care- the trend was observed across all level of facilities.

Providers claimed to accomplish good conduct with their clients in most of the cases while the opposite reports were received from the clients on exit interviews. The dissatisfactions from all corners concentrated on issues like poor hospital environment, supplies, overcrowding, bad toilet facilities etc. The findings have also emphasized on optimum utilization of available human resource, including making them available in adequate number and free of absenteeism especially more nurses for ensuring constant quality services. Inadequate/interrupted supplies, deficiencies non availability of anesthetists or obstetricians or both and lack of safe blood transfusion are the major obstacle for proper emergency obstetric services especially at upazilla and some of the district level facilities. Awareness building, gender responsiveness, respect to women rights and special fund for 
the poor were prioritized as issue to resolve during the focus group discussions.

Government is committed to improve access to quality of care in maternal and newborn health at all level of facilities and that necessary policy directions are being reiterated in many policy documents $^{7,8}$. In spite of continuous efforts, achievement in improving quality in care is in question especially in the maternal and newborn health area which actually covers two of the six millennium development goals (MDGs) i.e. MDG 4 and 5. Identification of laps and gaps in quality of care is crucial for the policy makers for further improvement and there by substantial reduction in maternal and newborn mortality. The main issues in under utilization of Government health facilities are not only the cost involvement but rather utilization of the available resources in a efficient way. The poor behavior of any health care provider or absenteeism can be readily changed with improved supervision, support and individual's motivation. Training not only on technical skills rather it must include management skills and BCC is crucially needed. Community awareness on the other hand might have a pressure group effect for improvement of services in maternal and newborn care- is essential. Accountability and punishment for ill conduct and incentives for good performance should be in place for encourage retention of doctors and nurses peripheral health centers. The continuous supply of drugs and equipments must be ensured at all health facilities. The benefits of a strategic results-oriented approach to health-system development with maternal, newborn and child care are central to any progress towards MDG $4 \& 5^{9}$. Thus the results in this study may lead to further study or can help health managers in taking steps to improve quality of care at their facilities.

Although there are limitations in the study including its small sample size, however, the findings will be useful in planning and formulating future policies to improve quality of maternal and newborn health care in facilities and that can accelerate reduction in maternal and neonatal mortality and morbidity in Bangladesh.

\section{References}

1. National Institute of Population Research and Training (NIPORT), ORC Macro, Johns Hopkins University, ICDDR,B. Bangladesh maternal health services and maternal mortality survey 2001. Dhaka, Bangladesh and Calverton, MD: NIPORT, ORC Macro, Johns Hopkins University, and ICDDR,B, 2003.

2. National Institute of Population Research and Training (NIPORT), Mitra and Associates, and Measure DHS. Bangladesh Demographic and Health Survey 2007 Preliminary Report. Dhaka, Bangladesh and Calverton, Maryland [USA]: National Institute of Population Research and Training, Mitra and Associates, and Measure DHS, 2007.

3. Conceptual Framework of Health, Nutrition and Population Sector Program (HNPSP) 2003-2010. MOHFW, 2003.

4. Bangladesh Demographic and Health Survey, 19992000. National Institute of Population Research and Training, 2001.

5. Bangladesh demographic and health survey. National Institute of Population Research and Training, 2007.

6. Yusuf HR, Akhter HH, Chowdhury ME, Rochat RW. Causes of death among women aged 10-50 years in Bangladesh. J Health Popul Nutr. 2007; 25: 302-11.

7. Majoko F, Chipato T, Iliff V. Trends in maternal mortality for the Greater Harare Maternity Unit: 1976 to 1997. Cent Afr J Med. 2001; 47: 199-203.

8. Health and Population Sector Programme 1998-2003 Bangladesh. Service delivery survey: Second cycle, 2000 Report. CIET Canada and Ministry of Health and Family Welfare, Government of Peoples' Republic of Bangladesh, Dhaka, 2001.

9. Poverty Reduction Strategy Paper. Government of Peoples’ Republic of Bangladesh. 